\title{
Modelling state dependence and feedback effects between poverty, employment and parental home emancipation among European youth *
}

\author{
SARA AYLLÓN \\ Departament d'Economia i Empresa \\ Universitat Pompeu Fabra ${ }^{\dagger}$
}

\begin{abstract}
Youth is one of the phases in the life-cycle when some of the most decisive life transitions take place. Entering the labour market or leaving parental home are events with important consequences for the economic well-being of young adults. In this paper, the interrelationship between employment, residential emancipation and poverty dynamics is studied for eight European countries by means of an econometric model with feedback effects. Results show that youth poverty genuine state dependence is positive and highly significant. Evidence proves there is a strong causal effect between poverty and leaving home in Scandinavian countries, however, time in economic hardship does not last long. In Southern Europe, instead, youth tend to leave their parental home much later in order to avoid falling into a poverty state that is more persistent. Past poverty has negative consequences on the likelihood of employment.
\end{abstract}

Keywords: youth poverty dynamics, trivariate multinomial probit, state dependence, feedback effects, unobserved heterogeneity

JEL classification: I32, J13, C33

\footnotetext{
${ }^{*}$ Correspondence to: Departament d'Economia i Empresa, Universitat Pompeu Fabra, C/ Ramon Trias Fargas 25-27, 08005 Barcelona, Spain. Phone number: +3493 542 1664. Fax: +3493 542 1746. E-mail: sara.ayllon@upf.edu

${ }^{\dagger}$ The author would like to thank Martin Biewen, Olga Cantó, Kari Hämäläinen, Alicia Rambaldi, Xavi Ramos and Philippe Van Kerm for comments on an earlier version of this paper. I also like to thank Arnstein Aassve for introducing me to programming with aML. Furthermore, I am grateful for the comments I received at the Workshop on 'Inequality and Poverty in the Global Economy' in Mannheim (March, 2009), at the 15th International Conference on Panel Data in Bonn (July, 2009), at the Workshop on 'Economic Uncertainty and Family Dynamics' in Berlin (July, 2009) and at the 21st EALE Conference in Tallinn (September, 2009). I am also very much grateful for the warm hospitality I received while visiting the Government Institute for Economic Research in Helsinki, Finland. Any errors or misinterpretations are my own. Financial support is greatly acknowledged from the Spanish project SEJ2007-67911-C03-02/ECON and Fundació Jaume Bofill.
} 


\section{Introduction}

The analysis of youth poverty dynamics has received little attention in the literature despite the considerable amount of interest devoted to the study of poverty transience and the development of youth poverty studies. In fact, in the last two decades, the literature on poverty dynamics has mainly focused on the adult population while youth poverty analyses have mainly been done from a static perspective. ${ }^{1}$

In this paper, we argue that a better understanding of youth poverty dynamics is necessary if we are to design effective policies at fighting it. Youth is a temporary phase in the life cycle when some of the most important life opportunities are decided yet we know very little about the nature of poverty while young. ${ }^{2}$

On the one hand, this paper is devoted to the analysis of youth genuine state dependence in the poverty status, that is, we analyse to what extent experiencing poverty in a given period has a causal effect on future poverty. We decompose youth poverty persistence caused by observed and unobserved heterogeneity from the one due to genuine state dependence. Distinguishing between the two has important consequences for the design of social policies aimed at fighting economic hardship. If youth poverty is driven by genuine state dependence, helping young people to move above the poverty line today will reduce their likelihood of experiencing poverty tomorrow. Instead, if youth poverty is mainly due to heterogeneity, policies will have to be addressed at enhancing those characteristics that are protective factors against economic disadvantage.

On the other hand, in this study, we argue that youth poverty cannot be measured independently from certain life transitions as they have lasting consequences on young people's economic well-being. More precisely, we analyse how poverty relates with employment and leaving parental home by modelling simultaneously the three outcomes and allowing for feedback effects. We claim that only by acknowl-

\footnotetext{
${ }^{1}$ See Jenkins (2000) for a review of the literature on modelling poverty transitions and Aassve, Iacovou, and Mencarini (2006) and Iacovou and Aassve (2007) for comprehensive surveys of youth poverty studies from a static point of view.

${ }^{2}$ As a matter of fact, the literature has been more concerned about the consequences of experiencing poverty during childhood than while young. Yet, it has not been proven that youth poverty has less long-lasting consequences for individuals than child poverty (see Hobcraft, 2003, for a similar argument).
} 
edging spill-over effects between the three processes, we can properly deal with the endogeneity problems that arise when studying life transitions possibly taking place in a sequential manner. As far as we know, similar estimates do not exist in the literature.

Thus, a particular contribution of the paper is the estimation of a dynamic trivariate probit model for poverty, employment and leaving parental home with feedback effects between the three processes (see Biewen, 2004, 2008) that allows the measurement of state dependence, accounts for the initial conditions problem (see Wooldridge, 2005), controls for unobserved heterogeneity and non-random selection of the sample. Improving the existing proposal in the literature, we unrestrict the cross-process unobserved correlation structure by allowing random effects to be different in each equation and freely correlated.

The questions this study aims at answering can be summarised as follows. Is poverty temporarily lived by youth across Europe or rather is of permanent nature? Is poverty persistence explained by genuine state dependence and/or by observed and unobserved individual characteristics? Can youth poverty dynamics be measured independently from leaving home decisions or labour market opportunities? What is the link between employment and residential emancipation and how do both phenomena relate with poverty? Importantly, we expect the results to differ according to the institutional settings, the generosity of the Welfare State provision, the dynamism of youth labour markets and the cultural values, among other factors.

Data is from the European Community Household Panel and transitions refer to the period between 1994 and 2000. Our analysis is based on Spain, Italy, Denmark, Finland, Germany, France, United Kingdom and Ireland. Thus, this is also a comparative analysis.

Main results show that there is a considerable degree of youth poverty genuine state dependence. Poverty today increases in itself the likelihood of being poor tomorrow among young individuals. Yet, this scarring effect is shortly lived in Scandinavia as compared to Southern or Continental Europe. Furthermore, past poverty decreases the likelihood of employment nearly everywhere while it only lessens the chances of residential emancipation in Italy and France. 
This paper is structured as follows. Next section revises the literature on youth poverty dynamics. Section 3 presents the data set used and our definitions of youth, poverty, employment and emancipation. Section 4 illustrates the relationships between poverty, employment and leaving home which allows foreseeing some of the effects that will be confirmed by the econometric model. Section 5 presents the econometric technique and Section 6 the empirical results. Section 7 summarises our main findings and discusses avenues for future research.

\section{Youth poverty dynamics in the literature}

Literature on youth poverty has mainly focused on the study of the economic situation of young individuals from a static perspective. Thanks to the availability of comparative data, we have a fairly good description of youth poverty patterns across the European Union (Middleton, 2002; Aassve, Iacovou, and Mencarini, 2006; Iacovou and Aassve, 2007). We have learnt about the importance of living with the family of origin, being in a stable job or having an employed partner as protecting factors against youth poverty (Iacovou and Berthoud, 2003). We also know better about the relationship between youth poverty and the life-cycle (Kangas and Palme, 2000; Rigg and Sefton, 2004) or between poverty and leaving parental home (Aassve, Iacovou, and Mencarini, 2006). Yet, our knowledge of youth poverty dynamics is still scarce. The existing literature is revised in what follows.

Aassve et al. (2005) study the impact of certain life events on the probability of entry into and exit from poverty amongst young people. Their results confirm that leaving the parental home (especially in Scandinavian Europe) and childbearing are associated with poverty entry while cohabitation with a partner stands as a protective factor against it. Furthermore, poverty exits are related with job stability and not just with employment or end of education.

The relationship between leaving the parental home and poverty entry is further studied in Aassve et al. (2007) and Parisi (2008). Using propensity score matching techniques and with a sample of 13 European countries, Aassve et al. (2007) confirm that residential emancipation strongly increases the risk of poverty entry in those 
countries where leaving home occurs early as in Denmark or Finland. The same is not true for countries where emancipation is delayed. In a similar fashion, Parisi (2008) estimates that, in Southern Europe, youth with those characteristics that make them more prone to leave, younger or from poorer family background are more likely to enter poverty when they emancipate.

Furthermore, Cantó and Mercader (2001a) study the economic consequences for the family of origin of youth emancipation in Spain. Their results show that leaving home increases the poverty entry rate of the remaining household members pointing to the fact that youth economic contribution in the parental home prior to emancipation is important in countries like Spain. Instead, no significant effect is observed in relation to poverty exits.

As for youth poverty duration, Mendola, Busetta, and Aassve (2008), even if without strictly modelling dynamics, study poverty persistence in several European countries by analysing the number of periods that an individual is recorded to be below the poverty line. Based on a generalised ordinal logit model, they find that despite of the high levels of poverty experienced by young people in Social Democratic countries, their poverty experience is very temporary in nature thanks to the generosity of the Welfare State provision and the dynamism of labour markets. Moreover, Cantó and Mercader (2001a) show that the presence of an employed youth in the parental household significantly reduces the probability of persisting in poverty in Spain by avoiding entrance if the household head is not employed and by promoting exit if employed.

Thus, the literature has highlighted the importance of leaving parental home and employment as key features to take into account when analysing poverty among young adults. Yet, none of the revised contributions considers the endogeneity / simultaneity problems that arise when modelling poverty in a time of demographic and labour market transitions. This is a drawback that we take up in this work by jointly modelling employment, residential emancipation and poverty while allowing for feedback effects and controlling for initial conditions and unobserved heterogeneity. As a result, we are able to present a measure of youth poverty genuine state dependence for each analysed country and estimates of scarring effects between the 
different processes.

\section{Data and definitions}

We use data from the European Community Household Panel (ECHP) which is a harmonised cross-national longitudinal survey collected across all members of the former European Union-15 between 1994 and 2001 - except for Austria and Finland that joined in 1995 and 1996, respectively. Our analysis is based on the components from Spain, Italy, Finland, Denmark, Germany, France, United Kingdom and Ireland. Possibly the greatest advantage of the ECHP is that a standardised questionnaire is answered each year by a representative sample of individuals and households which allows comparative analysis across countries as the one we propose here. On the negative side, only the population living in private households is represented in the ECHP thus, our study does not cover youth living in community housing or without stable accommodation.

Our working sample is restricted to those individuals between 16 and 29 years of age at the first time they participate in the panel. The lower end is because the ECHP contains detailed information for individuals 16 or older. The upper end may seem very high but in Southern Europe it is only in youth late twenties when most of the transitions to adulthood take place. ${ }^{3}$ Furthermore, the sample is an unbalanced panel which allows to draw the results from all the information available in the data set. The number of observations is detailed in the table A.1 of the Appendix.

Importantly note that poverty transitions can only be measured for the period between 1994 and 2000 (and 1996 to 2000 in the Finnish case). This is so because all the annual income variables are collected retrospectively in the ECHP. Thus, interviews that took place during the first wave of the panel in 1994 asked about the incomes obtained in 1993. As we do not want to neglect this time bias (see Debels and Vandecasteele, 2008), we build net household income at $t$ summing up the incomes of all individuals present in the household at $t-1$. This methodology leaves

\footnotetext{
${ }^{3}$ The European Commission proposed in the Laeken indicators aimed at the study of poverty and social exclusion the analysis of the age group between 16 and 24 . We find this age bound too restrictive in the case of our analysis.
} 
us with only seven waves to be used as we cannot build household income referred to 1993 because we do not know household composition for that year. Unfortunately, this methodological decision makes a certain number of missing values to arise when one of the household members attrit or does not inform about his/her income. Yet, we preferred to correct the time bias and deal with attrition within our methodology (see below).

Finally, and as for the definitions of the main variables of interest, we considered poor each young person with household equivalent income below $60 \%$ of the median, being the threshold time and country specific. Also incomes are made equivalent by using the modified OECD equivalence scale that gives a weight of 1 to the first member in the household, 0.5 to the rest of adults and 0.3 to children below 14 years of age. Furthermore, as normally set in poverty studies, we accept all individual incomes are pooled together and equally shared among members. We define that an individual is employed if s/he is normally working 15 or more hours per week according to a self-defined variable. And, finally, we consider as emancipated that young person that lives in a household where none of the registered members are his/her progenitors. ${ }^{4}$

\section{The relationship between youth poverty, employ- ment and leaving home}

\subsection{Poverty and the time of leaving home}

The relationship between poverty and the time of leaving home is analysed in Figure 1 which shows, for each country, youth poverty headcount during the four years before and after residential emancipation. In the figure, $t=0$ (marked with a vertical line) is the last period we observe young individuals in the parental home. Note that the sample in this case is limited to those individuals that are yet living with their parents the first time they participate in the panel and we observe them

\footnotetext{
${ }^{4}$ Throughout the paper, emancipation always refers to the residential status of the young individual and not to economic emancipation or other kind.
} 
leaving.

[FIGURE 1 AROUND HERE]

As already well documented in the literature, the most striking differences in the youth poverty rates before and after emancipation are found in Nordic countries while the least in the Mediterranean ones (see Aassve et al., 2005; Aassve, Iacovou, and Mencarini, 2006 and Aassve et al., 2007).

In Spain and Italy, the poverty risk keeps decreasing during the four years previous to leaving the parental home but it does so also during two or three years after emancipation. Young Mediterraneans remain in the parental home until they can economically guarantee themselves a smooth residential transition. The period prior to emancipation is taken by Italians and Spaniards as an opportunity to accumulate resources (savings, home ownership, human capital, etc.) that will assure a similar level of economic well-being while emancipated than the one enjoyed in their parental home. ${ }^{5}$ Note however the increase in the risk of poverty of Italians few years after emancipation explained by the fact that $58.8 \%$ of Italians would be in charge of at least one child in their fourth year out of the parental home while only $29.1 \%$ of Spaniards.

On the contrary, the poverty risk for Danish and Finnish youth it multiplies by 15 times between the year previous to emancipation and the first year outside the parental home. This is readily explained by the fact that leaving home is closely associated with pursuing education in both countries. For instance, in Denmark, at $t=0$, young individuals had a poverty risk of $2.3 \%$ while once out of the parental home $(t=1)$ it increases to $41.7 \%{ }^{6}$ Nevertheless, there is also, in both countries, a clear and fast pattern of poverty risk decrease in the successive years after emancipation. Thus, for the majority of youth, time in economic hardship does not last long.

\footnotetext{
${ }^{5}$ See Alessie, Brugiavini, and Weber (2006) on the effects of cohabitation on household savings decisions in Italy and the Netherlands.

${ }^{6}$ Notice how this descriptive analysis does not take into account the fact that home stayers and leavers may have different characteristics that make the latter more prone to leave home and enter poverty. The econometric model we present in the next section does take into account possible selection effects.
} 
The patterns of the poverty risk and the time of leaving home in Germany, France, UK and Ireland are somehow in between those observed for Mediterranean and Nordic countries. We can see a certain increase in the poverty risk when leaving parental home but it is smoother (especially in Ireland) than the one experienced by Danish and Finns.

For the analysis of the influence of poverty in the family of origin on the decision to leave parental home, we have computed emancipation rates separately for poor and non-poor youth. The same pattern emerges in all the analysed countries: youth emancipation rates are lower if the family of origin is in economic hardship as already found by Cantó and Mercader (2001b) for the Spanish case.

\subsection{Employment and leaving home decisions}

Figure 2 shows the percentage of employed and residentially emancipated youth by age group in each of the analysed countries. A vertical line at the age of 25 is drawn to ease comparison.

Interestingly, for Spain and Italy, but also for Ireland, the percentage of young people employed is always above the percentage of residentially emancipated, pointing out to the fact that for the majority of young individuals employment takes place earlier than emancipation. Survival analysis estimates for residential emancipation and entry into the labour market illustrate that young Italians and Spaniards spend 2 to 3 years working before leaving parental home depending on the age group. In Ireland, it takes up to 4 years for the age group 20 to $24 .^{7}$ This finding goes hand in hand with the commented results about the relationship between poverty and the decision to leave the parental home: youth delay their emancipation while accumulating enough human capital or economic resources until they feel prepared to leave. $^{8}$

\section{[FIGURE 2 AROUND HERE]}

\footnotetext{
${ }^{7}$ We use Kaplan-Meier estimates for the first time young people are employed and among those initially living with their parents.

${ }^{8}$ Jurado Guerrero (2001) argues that in Spain not leaving parental home under precarious economic conditions might even be a social norm.
} 
A similar pattern is found in the United Kingdom and Germany among youngest youth. Yet, emancipation and employment in both countries take place in a more simultaneous fashion for relatively late leavers (25 or older). Time between first job and leaving home is only around one year, shorter than for their Mediterranean counterparts.

In Northern Europe, instead, leaving home takes place much earlier and before entering the labour market, being the pattern especially clear in Finland. For the majority of Finns, and especially for those above 20, employment is not a necessary condition for emancipation. In Denmark, we observe the same pattern only for those 22 or older. The youngest group (16 to 21) leaves home approximately one year after having acquired the first job. Youngest youth with less employability search their first job while enjoying the economic security of being in the parental home.

Finally, in France, the percentage of youth that is employed is very similar to those residentially emancipated and survival analysis estimates prove both transitions take place simultaneously for many individuals. Jurado Guerrero (2001) argues that employment is less relevant for French youth chances of being residentially emancipated (especially for men) since market income is often combined with public benefits and family help.

In short, Figure 2 shows that the sequence of events is different in each country and its possible consequences on the economic well-being of young people are so as well.

\subsection{Youth employment and poverty}

In order to analyse the relationship between youth employment and poverty, we have computed the poverty risk of all individuals according to a household categorisation that takes into account the reference person age, his/her employment status, the presence of young individuals in the household and whether they have a job or not. ${ }^{9}$ We strictly follow the idea developed by Cantó and Mercader (2001b). ${ }^{10}$

First columns of Table 1 show the poverty risk of individuals living in a household

\footnotetext{
${ }^{9}$ The reference person in the ECHP is appointed by the household and it does not necessarily refer to the main income receiver but rather to the household head.

${ }^{10}$ See Cantó and Mercader (2001b), Table 9.5., p. 227.
} 
where the reference person is young. Unsurprisingly, the poverty risk is in mean around 5 times higher when the young individual is not employed than when is so. Employment proves once more to be a crucial protective factor against poverty.

[TABLE 1 AROUND HERE]

The effect of the presence of young people on their household poverty risk, shown in the rest of columns, very much depends on the employment status of youth. While nearly in every country the presence of not employed youth increases the chances of being poor, as opposed to households without young members, the poverty risk strongly decreases with youth employment, being the effect especially clear in households where the reference person is not employed. Notice nevertheless that even when this help-effect follows the same pattern in each of the analysed countries in terms of poverty reduction, it is much more common in Italy, Spain and Ireland see the percentages of individuals in each household type. ${ }^{11}$ In the just mentioned countries, remaining in the parental home while preparing the emancipation does not only benefit the young individual but also his/her progenitors in what can be seen as a family win-win strategy. ${ }^{12}$

\section{An econometric model of feedback effects bet- ween poverty, employment and leaving home decisions}

To study the described relationships between poverty, employment and leaving home decisions among European youth, we propose the estimation of a dynamic randomeffects trivariate probit model that allows for feedback effects between the three

\footnotetext{
${ }^{11}$ For the Spanish case, Cantó and Mercader (2001a) have been amongst the first to describe a help-effect that works from youth to parents especially in households where the head is unemployed or inactive. Similarly, Iacovou and Davia (2005) observe how it is in Southern Europe where adult children are more likely to be economically supporting their parents. Further, Kluve (2002) finds that in Southern Europe parents' financial satisfaction decreases when their young children leave their home while the contrary is found in Northern Europe.

${ }^{12}$ See Ayllón (2009) for an analysis of the increasing help-effect provided by young people over time in Spain,
} 
processes. We have chosen this model because it allows us to deal with the unrealistic assumption that each of the processes has no influence on future values of the outcomes - e.g. past poverty having no effect on current employment or past employment on current emancipation status. As a first-order Markov chain model, it allows estimating state dependence for each outcome and spill-over effects between the processes which assesses whether youth are confronted with a sequential process of decision making or not. ${ }^{13}$ Furthermore, the model controls for initial conditions and unobserved heterogeneity by following Wooldridge (2005) and allows free correlation between unobservables affecting each of the outcomes.

A similar econometric strategy has been applied before in different poverty analysis. ${ }^{14}$ Biewen $(2004,2008)$ is main reference to us. The author models poverty, employment and the decision to live with others amongst the adult population in Germany. Among other results, he finds that there is a considerable amount of genuine state dependence in the poverty status and that past poverty reduces the probability of employment in the future while has a positive effect on living alone (or household split). Yet, his model is limited by the use of a common individual specific random effect which restricts the cross-process unobserved correlation structure (Biewen, 2008, p. 13). In our case, we overcome this constraint by allowing random effects to be different in each equation and freely correlated thus making the model more flexible. Conceptually, we also find it easier to think that unobservables affecting poverty are different from those affecting employment or emancipation.

Devicienti and Poggi (2007) assess how poverty and social exclusion interact at the individual level in Italy. Their results on feedback effects show how both processes are affected by an important degree of state dependence and also how both phenomena reinforce each other. Amuedo-Dorantes and Serrano-Padial (2006), on the other hand, examine the poverty implications of past and current temporary

\footnotetext{
${ }^{13}$ Martínez-Granado and Ruiz-Castillo (2002) have modelled before the relationships between leaving parental home, entering the labour market and pursuing studies in the Spanish case. Yet, they assume that the three decisions are taken at the same point in time which we find unrealistic. As shown below, the completion of a process (e.g. employment) is for many individuals a necessary condition for entering another process (e.g. emancipation) in given contexts.

${ }^{14}$ Other applications not devoted to poverty analysis can be found in Alessie, Hochguertel, and Van Soest (2004) that studies the dynamics of risky financial assets ownership or Stewart (2007) for the interrelationship between unemployment and low-pay in Britain.
} 
employment in Spain. They find that holding a temporary contract increases not only the probability of current poverty but also of future poverty via an indirect effect that increases the chances of holding a type of contract in the future with higher poverty risk. ${ }^{15}$

In what follows, we focus first on the model specification. We discuss next the inclusion of the different feedback effects and finally the main model advantages and drawbacks.

\subsection{Model specification}

Let's define $P_{i t}$ as the individual poverty status of young individuals (measured at the household level), $E_{i t}$ the employment status in the labour market and $L_{i t}$ the emancipation status. We assume that in period $t$ individuals can be characterised by a latent poverty propensity $p_{i t}^{*}$, a latent employment propensity $e_{i t}^{*}$ and an emancipation propensity $l_{i t}^{*}$ that take the form:

$$
\begin{gathered}
p_{i t}^{*}=\beta_{0} E_{i t}+\beta_{1} L_{i t}+\beta_{2} P_{i t-1}+\beta_{3} E_{i t-1}+\beta_{4} L_{i t-1}+\beta_{5} Z_{i t}^{\prime}+c_{i}+u_{i t} \\
e_{i t}^{*}=\alpha_{0} L_{i t}+\alpha_{1} P_{i t-1}+\alpha_{2} E_{i t-1}+\alpha_{3} L_{i t-1}+\alpha_{4} S_{i t}^{\prime}+h_{i}+\epsilon_{i t} \\
l_{i t}^{*}=\gamma_{0} P_{i t-1}+\gamma_{1} E_{i t-1}+\gamma_{2} L_{i t-1}+\gamma_{3} V_{i t}^{\prime}+g_{i}+\lambda_{i t} \\
P_{i t}=I\left(p_{i t}^{*} \succ 0\right) \\
E_{i t}=I\left(e_{i t}^{*} \succ 0\right) \\
L_{i t}=I\left(l_{i t}^{*} \succ 0\right)
\end{gathered}
$$

where $i=1,2, \ldots, N$ refers to young individuals and $t=1, \ldots T$ are the number of periods under study. $I\left(p_{i t}^{*}\right) \succ 0, I\left(e_{i t}^{*}\right) \succ 0$ and $I\left(l_{i t}^{*}\right) \succ 0$ are binary indicator functions equal to one if the latent propensity in each case is positive and equal to zero otherwise. Further, $\left(Z_{i t}^{\prime}, S_{i t}^{\prime}, V_{i t}^{\prime}\right)$ are the independent variables vectors assumed to be exogenous, $\left(\beta_{0}, \beta_{1}, \beta_{2}, \beta_{3}, \beta_{4}, \alpha_{0}, \alpha_{1}, \alpha_{2}, \alpha_{3}, \gamma_{0}, \gamma_{1}, \gamma_{2}\right)$ are the feedback effects we

\footnotetext{
${ }^{15}$ Interestingly, the equation that models work status and type of contract is run by means of a multinomial logit. Unfortunately, they do not take into account living arrangements and therefore some of their results are driven by this fact - e.g. they find that a temporary contract is not significant in explaining poverty among young males, the reason being that most of them live in the parental home.
} 
are interested in (see below) and, generally called, $\left(\beta_{5}, \alpha_{4}, \gamma_{3}\right)$ the rest of parameters to be estimated. Furthermore, the idiosyncratic error terms in each process $\left(u_{i t}, \epsilon_{i t}\right.$ and $\lambda_{i t}$ ) are assumed to follow a standard normal distribution with zero mean and unit variance and to be serially independent.

As already well established in the literature, the treatment of initial conditions is crucial in the estimation of dynamic panel data models as the one proposed in equations 1 to $3{ }^{16}$ The problem of initial conditions arises because the start of the observation window may not be the same than the start of the outcome experience. Just as in Biewen (2004, 2008) and Devicienti and Poggi (2007), we have chosen to follow Wooldridge (2005) on the treatment of initial conditions. The author proposes to find the density of the dependent variables from $t=1, \ldots, T$ conditional on the initial condition and the explanatory variables — instead of finding the density for the whole period $t=0,1, \ldots, T$ given the explanatory variables. This implies the need to specify the density of the unobseved specific effects conditional on the dependent variables at $t=0$ and the time-averaged explanatory variables, called generally $\overline{Z_{i t}}$, $\overline{S_{i t}}$ and $\overline{V_{i t}} \cdot 17$ Formally, we can write the specification as follows,

$$
\begin{gathered}
c_{i}=a_{0}+a_{1} P_{i 0}+a_{2} E_{i 0}+a_{3} L_{i 0}+a_{4} \overline{Z_{i t}}+\kappa_{1 i} \\
h_{i}=b_{0}+b_{1} P_{i 0}+b_{2} E_{i 0}+b_{3} L_{i 0}+b_{4} \overline{S_{i t}}+\kappa_{2 i} \\
g_{i}=x_{0}+x_{1} P_{i 0}+x_{2} E_{i 0}+x_{3} L_{i 0}+x_{4} \overline{V_{i t}}+\kappa_{3 i}
\end{gathered}
$$

Following Stewart (2007), we add the time-averaged of some observed variables in order to allow for a correlation between the individual specific effects and the time-varying variables (see also Chamberlain, 1984 and Alessie, Hochguertel, and Van Soest, 2004)..$^{18}$

\footnotetext{
${ }^{16}$ See Hsiao (1986), Wooldridge (2005) and Chay and Hyslop (2000) for a review of the different strategies that have dealt with the initial conditions problem. Alessie, Hochguertel, and Van Soest (2004) approach, for instance, would imply to estimate three separate static equations for each outcome in the initial period $P_{i 0}, E_{i 0}, L_{i 0}$ and allow free cross-equation correlations. We find their methodology computationally difficult if we take into account that we have three outcomes under study and overall we would need to estimate a hexa-variate probit. Plus, and as recommended by Heckman (1981), initial conditions should be instrumented with background information which is very scarce in the case of the ECHP.

${ }^{17}$ In Biewen (2008), initial conditions are only included in the first equation as only one random effect is specified. We considered the need to introduce initial conditions in each equation as each includes an individual specific error.

${ }^{18}$ Stewart (2007) includes the average of all the model time-varying covariates except for feed-
} 
The joint density of the three outcomes $\left\{P_{i 1}, \ldots, P_{i T} ; E_{i 1}, \ldots, E_{i T} ; L_{i 1}, \ldots, L_{i T}\right\}$ given the exogenous variables $\left(Z_{i t}, S_{i t}, V_{i t}\right)$, the initial values $\left(Z_{i 0}, S_{i 0}, V_{i 0}\right)$ and the individual specific effects $\left(c_{i}, g_{i}, h_{i}\right)$ can be written as,

$$
\begin{array}{r}
f\left(P_{i 1}, \ldots, P_{i T} ; E_{i 1}, \ldots ; E_{i T}, L_{i 1}, \ldots, L_{i T} \mid Z_{i t}, S_{i t}, V_{i t}, P_{i 0}, E_{i 0}, L_{i 0}, c_{i}, h_{i}, g_{i}, \beta, \alpha, \gamma\right)= \\
=\prod_{t=1}^{T} f\left(P_{i t} \mid Z_{i t}, E_{i t}, L_{i t}, P_{i t-1}, E_{i t-1}, L_{i t-1}, c_{i}, \beta\right) \\
\cdot f\left(E_{i t} \mid S_{i t}, L_{i t}, P_{i t-1}, E_{i t-1}, L_{i t-1}, h_{i}, \alpha\right) \cdot f\left(L_{i t} \mid V_{i t}, P_{i t-1}, E_{i t-1}, L_{i t-1}, g_{i}, \gamma\right)= \\
=\prod_{t=1}^{T} \Phi\left[( 2 - P _ { i t } ) \left(\beta_{0} E_{i t}+\beta_{1} L_{i t}+\beta_{2} P_{i t-1}+\beta_{3} E_{i t-1}+\beta_{4} L_{i t-1}+\beta_{5} Z_{i t}^{\prime}+\right.\right. \\
\left.\left.+a_{0}+a_{1} P_{i 0}+a_{2} E_{i 0}+a_{3} L_{i 0}+a_{4} \overline{Z_{i t}}+\kappa_{1 i}\right)\right] \\
. \Phi\left[( 2 - E _ { i t } ) \left(\alpha_{0} L_{i t}+\alpha_{1} P_{i t-1}+\alpha_{2} E_{i t-1}+\alpha_{3} L_{i t-1}+\alpha_{4} S_{i t}^{\prime}+\right.\right. \\
\left.\left.+b_{0}+b_{1} P_{i 0}+b_{2} E_{i 0}+b_{3} L_{i 0}+b_{4} \overline{S_{i t}}+\kappa_{2 i}\right)\right] \\
. \Phi\left[( 2 - L _ { i t } ) \left(\gamma_{0} P_{i t-1}+\gamma_{1} E_{i t-1}+\gamma_{2} L_{i t-1}+\gamma_{3} V_{i t}^{\prime}+\right.\right. \\
\left.\left.+x_{0}+x_{1} P_{i 0}+x_{2} E_{i 0}+x_{3} L_{i 0}+x_{4} \overline{V_{i t}}+\kappa_{3 i}\right)\right]
\end{array}
$$

where $\Phi$ denotes the cumulative distribution function of a standard normal distribution. Estimates of the model's parameters are obtained by Conditional Maximum Likelihood (CML). ${ }^{19}$ Moreover, the recursive structure assures identification by providing a multiplicity of exclusion restrictions as discussed in Mroz and Savage (2006).

Following Wooldridge (2000, 2005) and in order to get consistent estimates, the residuals $\kappa_{1 i}, \kappa_{2 i}, \kappa_{3 i}$ are integrated out using a numerical integration algorithm based on Gauss-Hermite quadrature with 12 points - though we checked how results did not change when using 6 or $24 .^{20}$ A trivariate normal distribution with zero mean

back effects and year dummies. Wooldridge (2000) also underlines the importance of including interaction terms so that the model is saturated. Following Biewen (2008) we introduced interactions between the initial conditions and also with some observed values yet, it made no difference on the results and we decided to exclude them from the final specification.

${ }^{19}$ As argued in the aML software package User's Guide: "When a closed form solution to the integral does not exist, the likelihood may be computed by approximating the normal integral by a weighted sum over 'conditional likekihoods,' i.e., likelihoods conditional on certain well-chosen values of the residual" (aML User's Guide, 2003, p. 130.) The alternative would be to use Maximum Simulated Likelihood (see Alessie, Hochguertel, and Van Soest, 2004; Devicienti and Poggi, 2007 or Contoyannis, Jones, and Rice, 2004).

${ }^{20}$ The algorithm selects a number of support points and weights such that the weighted points approximate the normal distribution (see aML User's Guide, 2003). 
and $\sigma_{k_{j i}}^{2}$ variance is assumed for $\kappa_{1 i}, \kappa_{2 i}, \kappa_{3 i}$ which moreover are allowed to be freely correlated:

$$
\begin{aligned}
& \rho_{12}=\operatorname{corr}\left(\kappa_{1 i}, \kappa_{2 i}\right) \\
& \rho_{13}=\operatorname{corr}\left(\kappa_{1 i}, \kappa_{3 i}\right) \\
& \rho_{23}=\operatorname{corr}\left(\kappa_{2 i}, \kappa_{3 i}\right)
\end{aligned}
$$

where $\rho_{12}$ summarises the association between unobservable individual factors determining poverty status and employment. If $\rho_{12}$ is positive (negative) it means that those individuals more likely to be poor are also more (less) likely to be employed. Furthermore, $\rho_{13}$ accounts for unobserved heterogeneity between poverty and leaving home. When positive (negative) it means that unobservables that make young people more likely to be poor make them more (less) likely to be emancipated. And, finally, $\rho_{23}$ which relates unobserved heterogeneity between employment and emancipation. If positive, it means that unobserved characteristics that make youth more likely to be employed also make them more likely to be emancipated (e.g. intelligence, career driven, etc.). If negative, the other way round.

\section{$5.2 \quad$ State dependence and feedback effects}

As for state dependence, in the poverty equation, we include as explanatory variables poverty status at $t-1$ with the idea of capturing the sign and degree of true state dependence in the poverty status once observed and unobserved heterogeneity is controlled for. As argued by Weber (2002) and Devicienti and Poggi (2007), if we would not consider unobserved heterogeneity, true state dependence would be overestimated. We expect genuine state dependence in the poverty status to be positive everywhere. Yet, the coefficient of the poverty status at the initial year should point to the fact that persistence seems to be longer lasting in Mediterranean countries as opposed to Nordic ones. Recall Figure 1 in the descriptive section.

In terms of feedback effects, the poverty equation includes as explanatory variable whether the individual has left the parental home or not. According to the descriptive statistics, we should not find great differences of the poverty risk among emancipated and non emancipated youth in Mediterranean countries while much 
more so in Nordic ones. Yet, lagged emancipation status should reflect the fact that poverty decreases at a fast rate for Finns and Danish. And, finally, employment and lagged employment is included in the equation from which we expect a negative sign — both for emancipated and non emancipated youth.

In terms of the employment equation, and following the sequential conditioning structure proposed in Biewen (2004), we include as explanatory variables lagged employment status, current and lagged emancipation status and lagged poverty status. ${ }^{21}$ From lagged employment status we expect a positive sign in all the analysed countries as state dependence in employment is significant in the labour market (see Arulampalam, Booth, and Taylor, 2000; Stewart, 2007 and Heckman, 1981). Moreover, we count on a positive influence of emancipation status (current and lagged) on employment given a higher level of individual income is necessary to support oneself outside the parental home. Yet, as shown in Figure 2, emancipation does not necessarily have any influence on the employment status of Scandinavian youth.

Less clear is, as yet, the influence of lagged poverty status on the influence of employment. On the one hand, amongst those living in the parental home, one may think that economic hardship may precipitate young individuals to enter the labour market in order to help his/her family. If that would be the case, we could anticipate a positive sign between lagged poverty and current employment. On the other hand, it is also well known that poverty is intergenerationally transmitted thus individuals from an economic deprived background have less opportunities in the labour market. If this effect is strong, we can expect a negative sign — possibly, less strong in Nordic countries where the intergenerational transmission of poverty is highly mediated by more egalitarian educational systems and policies (see, for

\footnotetext{
${ }^{21}$ We have indeed chosen to model employment in the second equation rather than emancipation as we preferred the effect of current emancipation status on employment than the other way round - yet results went into the same direction when we did so. Furthermore, in Biewen (2008) the sequential conditioning scheme proposed in the earlier version of the paper (2004) by which outcome 3 enters as explanatory variable in equation 2 is replaced for a bivariate probit scheme where outcome 2 and 3 do not enter as explanatory variables in equations 3 and 2, respectively, and thus, both outcomes are treated symmetrically. We have chosen to include the emancipation status in the employment equation because we are interested in the effect of leaving home in labour market decisions. However, we checked that the rest of the results did not change much when we modelled a symmetric structure. Indeed, Biewen (2008) also underlines that the general results do not depend on this choice of specification. Moreover, note that in any case, we are not modelling a fully simultaneous model thus the consistency of our estimates is guaranteed (see Maddala, 1983).
} 
instance, Jäntti et al., 2006).

And, finally, as for the leaving home equation, we have included only lagged employment, emancipation and poverty statuses. As before we expect lagged employment to be positively related with emancipation — though not necessarily significant in Nordic countries where employment is not an inevitable condition for emancipation. Furthermore, we expect a highly significant and positive sign for lagged emancipation status measuring state dependence outside the parental home, as 'come-backs' are rare in the analysed countries. ${ }^{22}$ And, finally, the influence of lagged poverty status on leaving home decisions is difficult to predict. In the descriptive analysis of Section 4 it was argued that economic hardship in the family of origin does not seem to precipitate leaving parental home. Yet, an explanation for it is difficult to disentangle. In those contexts where family ties are strong, young individuals may feel more responsible about their parental well-being and thus remain in the parental home to offer help and companionship. On the other hand, individuals from poorer background may not only have fewer opportunities in the labour market but also emancipation possibilities.

Notice that if $\beta_{3}=\beta_{4}=\alpha_{1}=\alpha_{3}=\gamma_{0}=\gamma_{1}=0$, the recursive structure of the proposed model would not be necessary and we could consistently estimate the three equations separately with three univariate random-effects dynamic models with unobserved heterogeneity. If the mentioned coefficients would be different from zero but $\rho_{12}=\rho_{13}=\rho_{23}=0$, again, we could estimate the equations separately by assuming that the lagged values of each outcome used as explanatory variable are weakly exogenous. Otherwise, joint estimation is necessary in order to obtain consistent estimates, as argued.

\subsection{Model advantages and drawbacks}

One of the main advantages of this dynamic model is that it allows estimating state dependence while distinguishing between genuine state dependence in each poverty,

\footnotetext{
${ }^{22}$ We were concerned about the possible difficulties arising from estimating a probit model with unobserved heterogeneity for leaving home given the small variability in the data. However, the inclusion of the lagged variable assured that estimates did not change much even when increasing importantly the number of quadrature points.
} 
employment and emancipation status $\left(\beta_{2}, \alpha_{2}, \lambda_{2}\right.$, respectively) and unobserved heterogeneity related to each outcome $\left(c_{i}, h_{i}\right.$ and $\left.g_{i}\right)$. Poverty genuine state dependence occurs because poverty in a given year may in itself increase the probability of being poor next year. Unobserved heterogeneity would explain persistence in a given status because those characteristics which make someone poor exhibit persistence over time. Further, the model estimates spill-over effects by separating dependence between outcomes $\left(\beta_{0}, \beta_{1}, \beta_{2}, \beta_{3}, \beta_{4}, \alpha_{0}, \alpha_{1}, \alpha_{2}, \alpha_{3}, \gamma_{0}, \gamma_{1}, \gamma_{2}\right)$ from correlated unobserved heterogeneity.

Note the importance for policy design of distinguishing genuine state dependence from observed and unobserved heterogeneity. Both phenomena can explain why an individual is consecutively poor but, as pointed out by Devicienti and Poggi (2007), if state dependence exists and it is positive, policies aimed at fighting youth poverty today are effective in reducing poverty tomorrow. If feedback effects are true, improving the chances of young people in the labour market will have spillover effects on the reduction of youth poverty. Instead, if poverty is mainly due to unobserved heterogeneity it will be very hard for social policy to tackle it.

Another important advantage of the model is that it allows attrition to depend on the initial conditions in an arbitrary way. The MLE allows a different attrition probability depending on the initial value of each of the outcomes. Thus, attrition is taken into account without need to explicitly model it. ${ }^{23}$

As argued by Biewen (2004, 2008), not allowing for serial correlation in the idiosyncratic error terms is a limitation of this kind of model but it would be exceedingly difficult to estimate it given the multiple equations structure of the current model. However, it opens an interesting avenue for future research. ${ }^{24}$

\footnotetext{
${ }^{23}$ See Cappellari and Jenkins $(2002$, 2004), for a methodology on poverty transitions that explicitly models sample retention.

${ }^{24}$ See Hyslop (1999) for an analysis of labour force participation of married women with a random-effects dynamic model that accounts for initial conditions, unobserved heterogeneity and also autocorrelation in the transitory error component or Contoyannis, Jones, and Rice (2004) in a study of individual health using similar techniques.
} 


\section{Empirical results}

We present our empirical findings by focusing first on the results related to unobserved heterogeneity and its correlations. Next, we move to a discussion of our findings relative to state dependence and feedback effects. To ease interpretation, we also present results as average partial effects (APE) which show, in absolute terms, the impact of a change in an explanatory variable on the risk of poverty, employment or emancipation. ${ }^{25}$ For example, the average partial effect of genuine state dependence in the poverty status is formally given by,

$$
\begin{array}{r}
A P E=E\left[P\left(P_{i t=1} \mid E_{i t}, L_{i t}, P_{i t-1}=1, E_{i t-1}, L_{i t-1}, P_{i 0}, E_{i 0}, L_{i 0}, Z_{i t}\right)-\right. \\
\left.-\left(P_{i t=1} \mid E_{i t}, L_{i t}, P_{i t-1}=0, E_{i t-1}, L_{i t-1}, P_{i 0}, E_{i 0}, L_{i 0}, Z_{i t}\right)\right]
\end{array}
$$

with the expectation being over all characteristics indexed by $i$. And consistently estimated by,

$$
\begin{array}{r}
\widehat{A P E}=N^{-1} \sum_{i=1}^{N}\left[\Phi \left(\beta_{0}^{o} E_{i t}+\beta_{1}^{o} L_{i t}+1 \cdot P_{i t-1}+\beta_{3}^{o} E_{i t-1}+\beta_{4}^{o} L_{i t-1}+\beta_{5}^{o} Z_{i t}^{\prime}+\right.\right. \\
\left.+a_{0}^{o}+a_{1}^{o} P_{i 0}+a_{2}^{o} E_{i 0}+a_{3}^{o} L_{i 0}+a_{4}^{o} \overline{Z_{i t}}\right)- \\
-\left(\beta_{0}^{o} E_{i t}+\beta_{1}^{o} L_{i t}+0\right. \\
\cdot P_{i t-1}+\beta_{3}^{o} E_{i t-1}+\beta_{4}^{o} L_{i t-1}+\beta_{5}^{o} Z_{i t}^{\prime}+ \\
\left.\left.+a_{0}^{o}+a_{1}^{o} P_{i 0}+a_{2}^{o} E_{i 0}+a_{3}^{o} L_{i 0}+a_{4}^{o} \overline{Z_{i t}}\right)\right]
\end{array}
$$

where superscript $o$ is used to denote that the original parameter estimated have been multiplied by $\left(1+{\widehat{\sigma_{c_{i}}}}^{2}\right)^{(-1 / 2)} \cdot{ }^{26}$

\subsection{Unobserved heterogeneity and correlations}

The estimated standard deviations of the random effects and their correlations are presented in Table 2. Importantly, the standard deviations for all random effects are statistically significant at $99 \%$ confidence level (except for one in the case of Ireland) which emphasizes the importance of considering unobserved heterogeneity in the present analysis.

\footnotetext{
${ }^{25}$ Note we have only computed APE for underlying coefficients statistically significant at least at $95 \%$ confidence level.

${ }^{26}$ Multiplying by this constant does make the results comparable with other econometric strategies such as pooled probit (see Arulampalam, 1999) and also it allows comparison with Biewen (2008).
} 


\section{[TABLE 2 AROUND HERE]}

Table 2 also presents the free correlations between unobservables. Recall that the significance of the correlations highlights the importance of estimating the three processes jointly. As can be seen, except for Ireland, in all countries, there is at least one correlation being significant. Yet, results also underline that not everywhere the three processes are similarly interlinked through unobserved heterogeneity. That is, the sequencing scheme does fit better certain contexts (namely Continental and Mediterranean countries) compare to others (Ireland or Finland). ${ }^{27}$

Unobserved factors driving poverty are negatively associated with those that drive employment in Germany and United Kingdom, and less strongly, in Denmark and Finland. It is reasonable to think that unobservables that make individuals more likely to be poor also reduce their chances to be employed. Interestingly, this same correlation is not significant in Mediterranean countries. Any interpretation of this result is difficult, yet it is possible to think that in strong family ties countries, young people may feel forced to enter the labour market in order to help their families out of poverty. And, as a result, off-set the difficulties they encounter when looking for a job. ${ }^{28}$

On the other hand, only in Spain and France, unobservable factors that drive poverty also drive emancipation. Actually, Parisi (2008) also proves for Southern Europe that, controlling for observed factors, the more likely is a young person to leave home, the more likely is to be poor once emancipated. Differently, we did not find such clear evidence in the case of Italy.

Finally, unobservables that make someone more likely to be employed also make him/her more likely to leave parental home in Mediterranean Europe - e.g. will for self-sufficiency, career driven, etc. Interestingly, the same is not true in Continental Europe. Actually, unobservable factors driving employment are negatively related

\footnotetext{
${ }^{27}$ Notice however, that in the case of Finland we only have data for the period 1996 to 2000 .

${ }^{28}$ See Cantó and Mercader (2001b, 2001b) and Martínez-Granado and Ruiz-Castillo (2002) for the argument that in Spain the inter-generational family provides support not only from parents to children but also from children to parents. Furthermore, Iacovou and Davia (2005) conclude that it is in the Southern European countries that adult children are most likely to be supporting their parents.
} 
with factors driving emancipation which highlights the fact that many Germans and French leave parental home for other reasons than employment.

\subsection{Poverty}

Table 3 presents the estimated parameters of main interest - the full specification of the model and standard errors are shown in Table A.1 of the Appendix. ${ }^{29}$ First rows show the results of the poverty equation. As expected, poverty status at $t-1$ is positive and highly significant in each of the analysed countries which proves the existence of a positive poverty genuine state dependence effect. As among the adult population, being poor today increases in itself the chances of being poor tomorrow also for young people. APE in Table 4 indicate that poverty genuine state dependence goes from 16 to 32 percentage points.

\section{[TABLE 3 AROUND HERE]}

\section{[TABLE 4 AROUND HERE]}

Yet, the nature of the poverty experience is very different depending on the institutional context. Danish and Finns do face problems of economic hardship during their youth however results show it is a situation of more temporary nature as the coefficient for $P_{0}$ is smaller than for $P_{t-1}$. Instead, in Mediterranean Europe, young people face more difficulties to escape poverty. As a matter of fact, the scarring effect of poverty increases with time which points to poverty experiences more persistent in nature - being the results especially clear in Spain, Italy and Ireland. Youth may be a temporary phase in the life cycle yet these results show poverty is not. The cases of Germany, France and United Kingdom lie in between.

Results also show how being outside the parental home is strongly associated with poverty in Finland and Denmark, but also in the rest of countries except for the Mediterranean ones where the coefficient is not significant. In Finland, for instance, emancipation implies an increase in the poverty risk of $48.6 \%$. Notice however, how in most countries (except Italy), the sign reverses and becomes negative for those

\footnotetext{
${ }^{29}$ As Mroz and Savage (2006) argue, the estimates can be interpreted as the impact of exogenously induced changes in the possibly endogenous determinants.
} 
that have been away from the parental home at least for two years $\left(L_{t-1}\right)$. This result highlights the temporality of economic hardship because of emancipation lived by Finns and Danish, but also Germans, French or British. ${ }^{30}$ In Spain and Italy, we do not find evidence of differences statistically significant between the poverty risk of leavers and stayers (see Mendola, Busetta, and Aassve, 2008, for a similar result). As argued, Mediterranean youth do not leave parental home until they can guarantee themselves a sufficient standard of living. ${ }^{31}$

As for the labour market, unsurprisingly, we find current and lagged employment to be significant and negatively related with the poverty status - being in Finland, France and Ireland where the effect is the strongest. Yet, the effect of employment on current poverty seems limited in terms of time as coefficients lose importance and may even reverse the sign.

The significance of the rest of variables that control for age, sex, region at the initial period or time varies depending on the context. ${ }^{32}$

\subsection{Employment}

As for the results in the employment equation, the only common coefficient being significant across all countries is the one capturing genuine state dependence in the employment status which is positive and significant, as expected. The highest genuine state dependence in the employment status is found in Germany and Italy and the weakest in Finland and Ireland. For instance, in Germany, past employment increases by 29 percentage points the likelihood of current employment among young people - this is slightly lower than the one found by Biewen (2008) among German men aged 26 to $65(33 \%)$.

\footnotetext{
${ }^{30}$ In Aassve et al. (2007) it is argued that Nordic youth perceive that the time in economic hardship will be short given the dynamism of youth labour markets and the generosity of the Welfare States and thus emancipation is the result of a rational decision.

${ }^{31}$ It is also true that young people in Mediterranean countries mostly leave parental home to live with a partner, thus, benefiting from the economies of scale of partnering. Notice also how the sign of leaving home in the initial period is positive and significant in Spain probably pointing out at the difficulties encountered by those that left parental home in their early youth. As noted by Parisi (2008), the later youth leave parental home the less likely are to enter poverty when they do leave. Similarly, in Italy, the sign for past emancipation status is positive and significant, most likely explained by young people starting to be engaged in childbearing.

${ }^{32}$ Note controls for education are necessarily left out of the regressions in order to avoid problems of endogeneity with leaving home.
} 
On the other hand, current emancipation status is not significant in Scandinavia and the English-speaking countries pointing out that employment and emancipation are not so interlinked phenomena. Conversely, in Continental and Mediterranean Europe the association between emancipation and employment is strong: leaving parental home increases the incentives to seek employment. Surprisingly, though, the coefficient for lagged emancipation status on employment is negative in Spain, Italy and France. Separate regressions by gender show that these results are driven by females who are less likely to be employed once they have been emancipated at least for two years and may be engaged in childbearing.

As for the influence of lagged poverty on employment, we were not sure whether to expect a positive sign - indicating that young individuals precipitate to the labour market to help their families out of economic hardship — or a negative one pointing out a certain degree of intergenerational poverty transmission. Our results show that the effect of poverty being transmitted across generations dominates and takes the form of lesser opportunities in the labour market. In Italy, for instance, past poverty reduces the chances of employment in the labour market by $7.5 \%$. However, notice how the coefficient is not significant in Finland and less precisely estimated in Denmark conforming to the well-known fact that the transmission of poverty across generations is less important in these countries.

Finally, girls are less likely to be employed in all the countries and age follows the usual inverted U-shape.

\subsection{Emancipation}

As expected, having left the parental home in the emancipation equation is positive and one of the most significant coefficients across equations. Young people that decide to leave the parental home are only in rare occasions coming back to it. Yet, it is in Ireland and in the Mediterranean countries where state dependence in the emancipation status is the strongest. Conversely, in Finland and Denmark the decision to leave the parental home is much more determined by age than by past emancipation decisions.

Lagged employment status is positive in Mediterranean and Continental Europe 
indicating that employment is a prerequisite to emancipation, especially among males. ${ }^{33}$ Finally, and in relation to lagged poverty status, interestingly, the coefficient is negative and significant only in France and Italy while not precisely estimated in the other strong family ties country as Spain. ${ }^{34}$ In France and Italy, poverty delays emancipation while economic hardship in the family of origin does not among Spaniards once other factors are controlled for.

Age is a strong determinant of leaving home decisions while girls are more likely to leave parental home than boys - as already well established in the literature.

\section{Conclusions}

This paper studies the dynamics of youth poverty in eight European countries using data from the European Community Household Panel for the period 1994-2000. Our main objective has been to separate genuine state dependence in the poverty status from observed and unobserved characteristics. To explore the nature of youth poverty, we have used a dynamic trivariate probit model with random effects that controls for unobserved heterogeneity and initial conditions while considers the possible endogeneity of employment and residential emancipation from the parental home by allowing for feedback effects and free correlation between random effects. We have followed the model proposed in Biewen (2004) but yet we have made the error's structure more flexible by adding a different random effect in each of the outcome equations.

Our results confirm that there is a considerable amount of genuine state dependence in the poverty status in all the analysed countries For instance, past poverty increases the chances of being poor in Italy by $20 \%$ and nearly $32 \%$ in Denmark. Yet, the coefficient of initial poverty status also indicates that the poverty experiences are very different in nature depending on the institutional context. Thus, poverty persistence is longer lasting in Mediterranean countries as opposed to Scandinavia.

\footnotetext{
${ }^{33}$ Results are not very apparent yet, note that the relationship between employment and emancipation is already accounted for in the employment equation.

${ }^{34}$ Parisi (2008) also finds a negative association between family poverty at $t$ and leaving home at $t+1$ for a pooled regression for all Southern Europe countries available at the ECHP. However, interaction terms with country show that coefficients are not precisely estimated for Spain.
} 
Germany, France and United Kingdom lie in between while Ireland behaves very much as a Mediterranean country. Genuine state dependence in the employment and emancipation status is positive and strong, as expected.

The results of the estimation suggest the importance of the feedback effects considered - though with different results in different institutional contexts. First, emancipation has proven to have barely any effect on poverty in Italy and Spain while important and positive in the rest of countries (especially in Finland and Denmark). Yet, in Scandinavian countries, the influence of emancipation on poverty is limited in terms of time as the sign for lagged emancipation status becomes negative. That is, emancipation increases the chances of being poor but not for a long time. Second, poverty decreases the chances of youth employment everywhere (except Finland) between 4 and 8 percentage points. Third, employment and emancipation are very close phenomena in Spain and Italy but also in Germany and France. In Scandinavian countries and in the English-speaking ones such a link does not seem to exist. And, finally, past poverty has a negative influence on emancipation yet evidence of such strong family ties seems limited only to Italy and France.

As for the model specification, results confirm the importance of considering unobserved heterogeneity and the correlations between random-effects. Yet, the link between the three estimated processes via unobservables is not equally strong in all countries. Actually, it is in Mediterranean and Continental Europe where a joint model of the kind presented here is more relevant.

Results call therefore for two type of policies aimed at fighting youth poverty. On the one hand, income policies that rise youth (or their family) incomes above the poverty line would avoid the scarring effect of poverty on future economic hardship. And, on the other hand, policies that enhance those characteristics observed to have an effect against poverty via employment or smoother residential transition.

There are several ways in which the results found in this paper can be extended. Some of the avenues for future research have already been commented along the text such as the incorporation of serially temporarily correlated error terms but also the introduction of second order lags. Another possible extension would be to model the different destinations of young people when leaving parental home or the scarring 
effect of unemployment periods on the likelihood of poverty and leaving home. 


\section{References}

Aassve, A., M. A. Davia, M. Iacovou, and S. Mazzuco (2007): "Does leaving home make you poor? Evidence from 13 European countries," Journal of Population Economics, 23, 315-338.

Aassve, A., M. A. Davia, M. Iacovou, and L. Mencarini (2005): "Poverty and the transition to adulthood: Risky situations and risky events," Working Paper 2005-23, ISER.

Aassve, A., M. Iacovou, and L. Mencarini (2006): "Youth poverty and transition to adulthood in Europe," Demographic Research, 15(2), 19-50.

Alessie, R., A. Brugiavini, and G. Weber (2006): "Saving and cohabitation: The economic consequences of living with ones own parents in Italy and the Netherlands," in NBER International seminar on Macroeconomics 2004, ed. by R. H. Clarida, J. A. Frankel, F. Giavazzi, and K. D. West. Cambridge: The MIT Press.

Alessie, R., S. Hochguertel, and A. Van Soest (2004): "Ownership of stocks and mutual funds: A panel data analysis," The Review of Economics and Statistics, 86(3), 783-796.

Amuedo-Dorantes, C., and R. Serrano-Padial (2006): "Labour market flexibility and poverty dynamics: Evidence from Spain," unpublished Working Paper.

Arulampalam, W. (1999): "Practitioners'corner. A note on estimated coefficients in random effects probit models," Oxford Bulletin of Economics and Statistics, $61(4), 597-602$.

Arulampalam, W., A. Booth, and M. Taylor (2000): "Unemployment persistence," Oxford Economic Papers, 52(1), 24-50.

AYllón, S. (2009): "Poverty and living arrangements among youth in Spain, 19802005," Demographic Research, 20(17), 403-434. 
BiEWEn, M. (2004): "Measuring state dependence in individual poverty status. Are there feedback effects to employment decisions and household composition?," IZA Discussion Papers 1138, Institute for the Study of Labor (IZA).

(2008): "Measuring state dependence in individual poverty histories when there is feedback to employment status and household composition," Paper presented at the 20th EALE Annual Conference, Amsterdam, Holland, September 18-20 2008, forthcoming Journal of Applied Econometrics.

Cantó, O., and M. Mercader (2001a): "Pobreza y familia: son los jóvenes una carga o una ayuda?," Papeles de Economía Española, 88, 151-165.

- (2001b): "Young people leaving home: the impact on poverty in Spain," in The Dynamics of Child Poverty in Industrialised Countries, ed. by B. Bradbury, S. Jenkins, and J. Micklewright. UNICEF, Cambridge University Press.

Cappellari, L., and S. P. Jenkins (2002): "Who stays poor? Who becomes poor? Evidence from the British Household Panel Survey," The Economic Journal, 112(478), C60-C67.

(2004): "Modelling low income transitions," Journal of Applied Econometrics, 19, 593-610.

Chamberlain, G. (1984): "Panel Data," in Handbook of Econometrics, ed. by Z. Giliches, and M. Intriligator, vol. 2, pp. 1247-1318. Amsterdam, North Holland.

Chay, K. Y., And D. Hyslop (2000): "Identification and estimation of dynamic binary response panel data models: Empirical evidence using alternative approaches," unpublished Working Paper.

Contoyannis, P., A. M. Jones, and N. Rice (2004): "Simulation-based inference in dynamic panel probit models: An application to health," Empirical Economics, 29, 49-77.

Debels, A., And L. VAndecasteele (2008): "The time lag in annual householdbased income measures: assessing and correction the bias," Review of Income and Wealth, 54(1), 71-88. 
Devicienti, F., And A. Poggi (2007): "Poverty and social exclusion: two sides of the same coin or dynamically interrelated processes?," Working Paper 62, Laboratorio R. Revelli.

Heckman, J. J. (1981): "Heterogeneity and state dependence," in Studies in Labor Markets, ed. by S. Rosen, pp. 91-139. The University of Chicago Press.

HobCRAFt, J. (2003): "Continuity and change in pathways to young adult disadvantage. Results from a British Birth Cohort," CASEpaper 56, Centre for Analysis of Social Exclusion, London School of Economics.

Hsiao, C. (1986): Analysis of panel data. Cambridge University Press.

Hyslop, D. R. (1999): "State dependence, serial correlation and heterogeneity in intertemporal labor force participation of married women," Econometrica, 67(6), $1255-1294$.

Iacovou, M., And A. Aassve (2007): Youth poverty in Europe. Joseph Rowntree Foundation.

IAcovou, M., And R. Berthoud (2003): "Employment and poverty among young people. A European perspective," Representing Children, 15(4), 258-270.

Iacovou, M., And M. A. Davia (2005): "Who supports whom? Co-residence between young adults and their parents," Paper presented at the EPUNet Conference 2006, Universitat Pompeu Fabra, Barcelona, Spain, May 8-9 2006.

Jäntti, M., K. Red, R. Naylor, A. Bjrklund, B. Bratsberg, O. RaAum, E. ÖsterbackA, AND T. ERIKSson (2006): "American exceptionalism in a new light: A comparison of intergenerational earnings mobility in the Nordic Countries, the United Kingdom and the United States," Discussion Paper 1938, Institute for the Study of Labor, Bonn.

Jenkins, S. P. (2000): "Modelling household income dynamics," Journal of Population Economics, 13, 529-567. 
Jurado Guerrero, T. (2001): Youth in transition. Housing, employment, social policies and families in France and Spain. Ashgate.

Kangas, O., And P. Palme (2000): "Does social policy matter? Poverty cycles in OECD countries," International Journal of Health Services, 30(2), 335-352.

KLuve, J. (2002): "Why not stay home? Determinants of nest-leaving behaviour in Germany and Spain," unpublished Working Paper, UC Berkeley.

MAdDALA, G. (1983): Limited-dependent and qualitative variables in Econometrics. Cambridge: Cambridge University Press.

Martínez-Granado, M., and J. Ruiz-Castillo (2002): "The decisions of Spanish youth: A cross-section study," Journal of Population Economics, 15, $305-330$.

Mendola, D., A. Busetta, and A. Aassve (2008): "Poverty Permanence Among European Youth," ISER Working Papers 2008-04, Institute for Social and Economic Research.

Middleton, S. (2002): "Transitions from youth to adulthood," in Poverty and Social Exclusion in Europe, ed. by M. Barnes, C. Heady, S. Middleton, J. Millar, F. Papadopoulos, G. Room, and P. Tsakloglou. Cheltenham: Edward Elgar.

Mroz, T. A., And T. H. SAvage (2006): "The long-term effects of youth unemployment," Journal of Human Resources, XLI(2), 259-293.

PARISI, L. (2008): "Leaving home and the chances of being poor: the case of young people in Southern European countries," Labour, 22(special issue), 89-114.

RigG, J., And T. Sefton (2004): "Income dynamics and the life cycle," CASEpaper 81, Centre for Analysis of Social Exclusion and London School of Economics.

Stewart, M. B. (2007): "The interrelated dynamics of unemployment and lowwage employment," Journal of Applied Econometrics, 22(3), 511-531. 
WEBER, A. (2002): "State dependence and wage dynamics. A heterogeneous Markov chain model for wage mobility in Austria," Economic Series 114, Institute for Advanced Studies (Vienna).

Wooldridge, J. M. (2000): "A framework for estimating dynamic, unobserved effects panel data models with possible feedback to future explanatory variables," Economic Letters, 68, 245-250.

(2005): "Simple solutions to the initial conditions problem in dynamic, non linear panel data models with unobserved heterogeneity," Journal of Applied Econometrics, 20, 39-54. 
Figure 1: Youth poverty rate and the time of leaving home

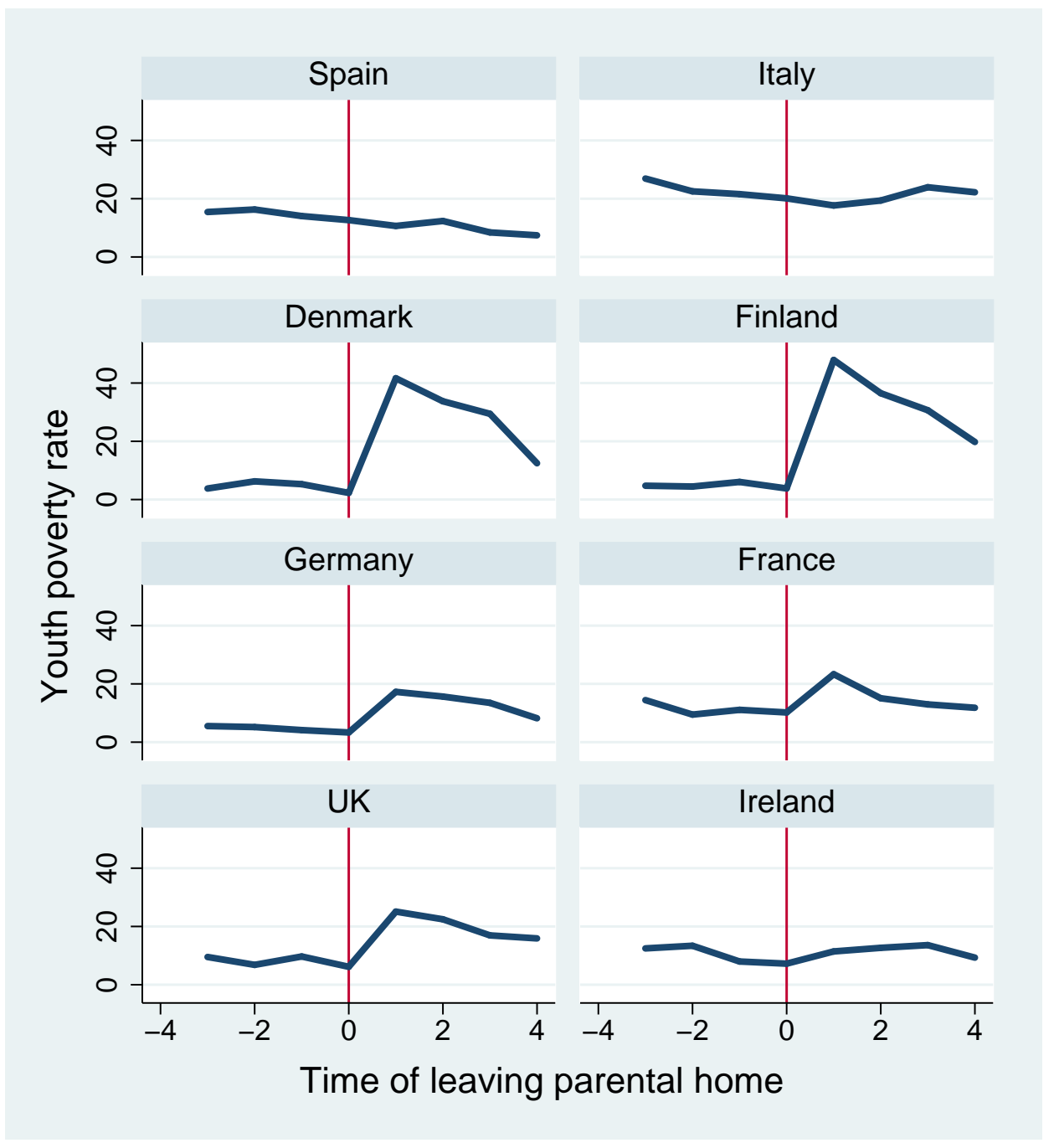

Source: Own calculations on the ECHP, 1994-2001. 
Figure 2: Percentage of employed and residentially emancipated youth by age group

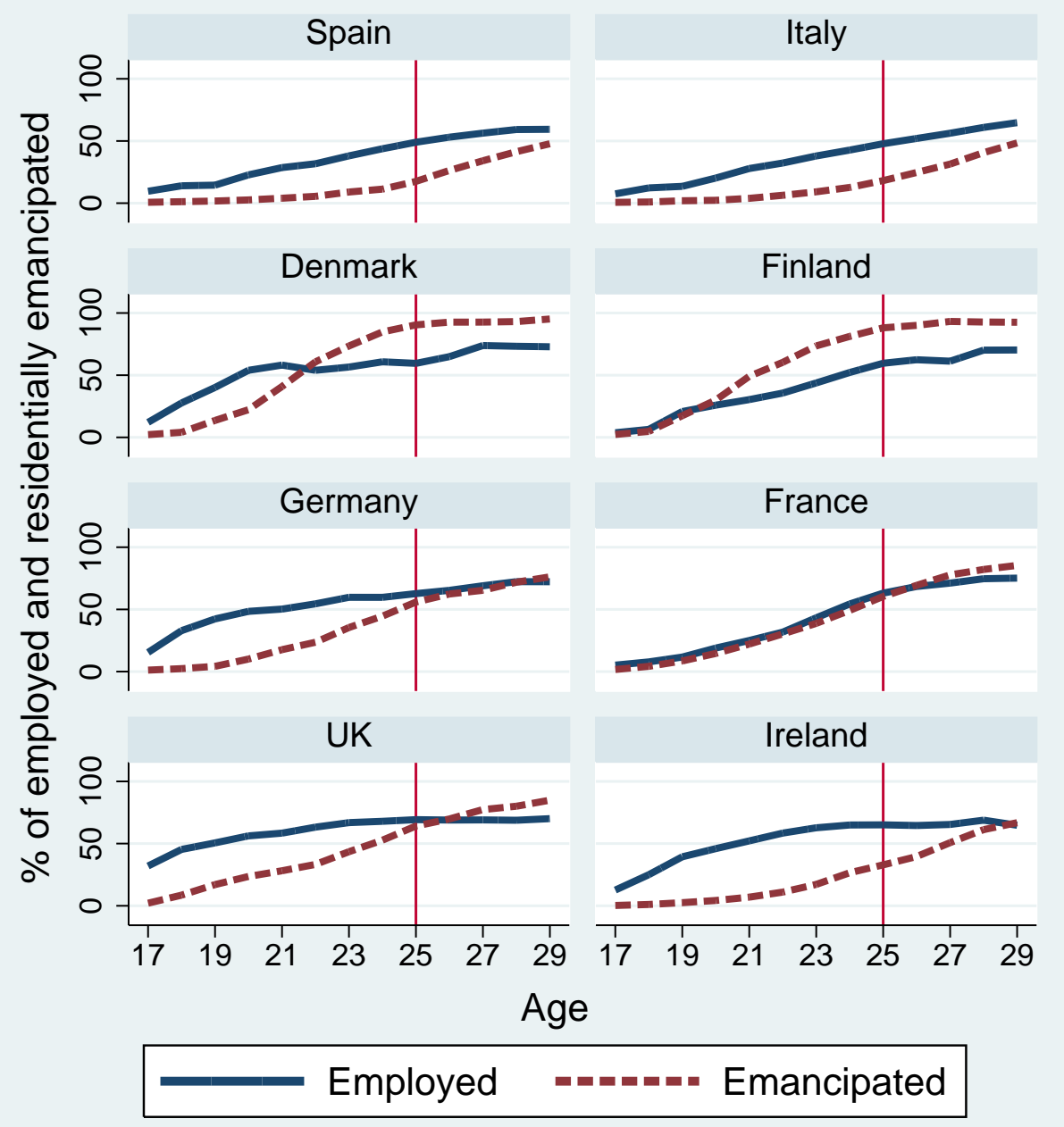

Source: Own calculations on the ECHP, 1994-2001. 


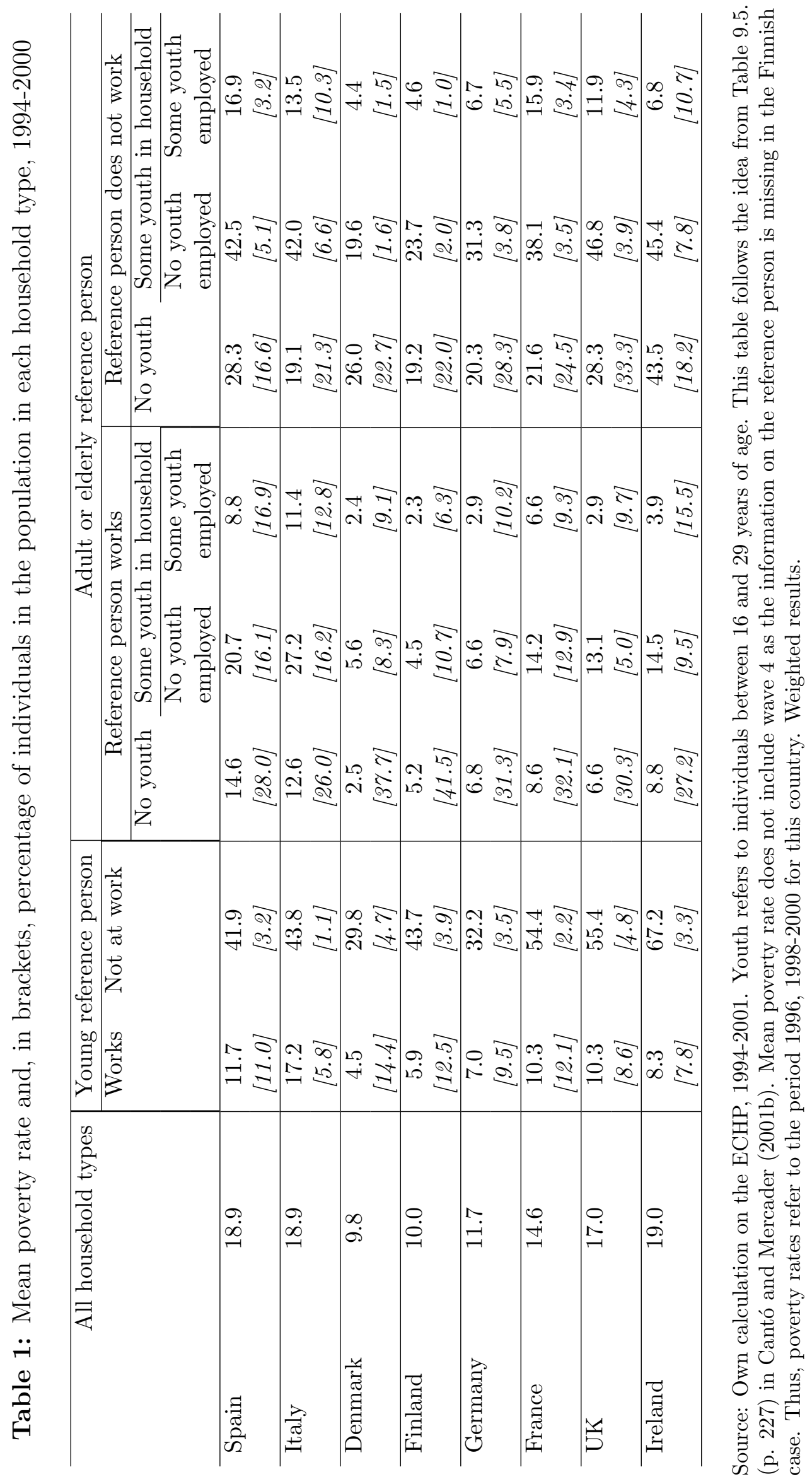




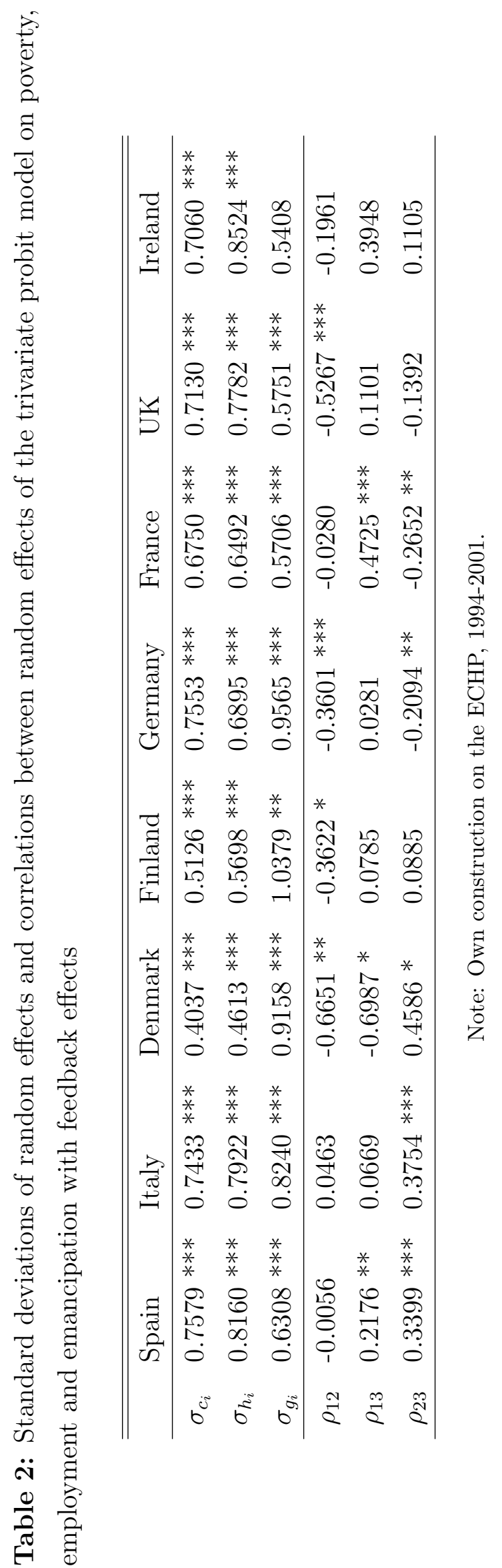




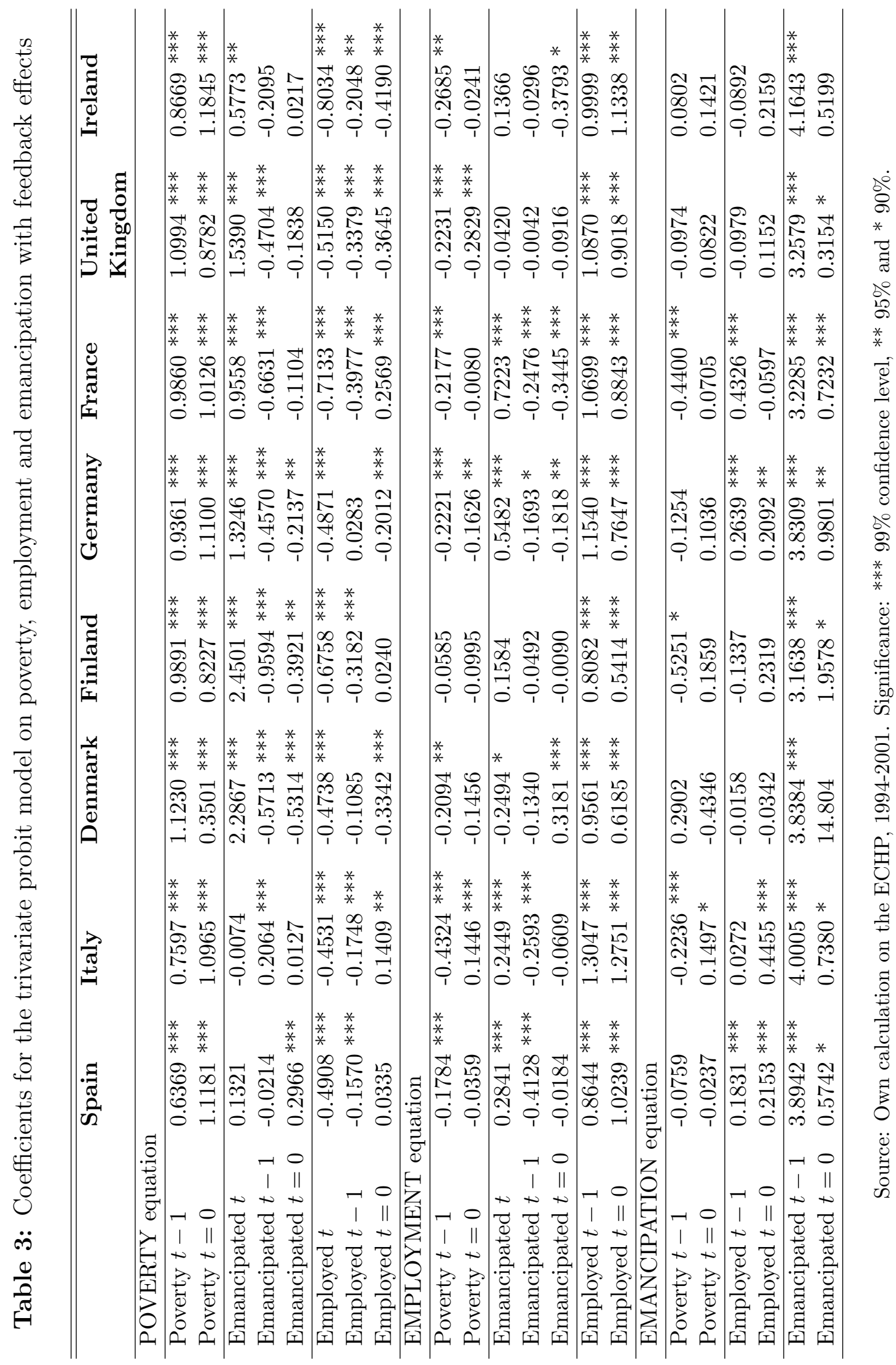




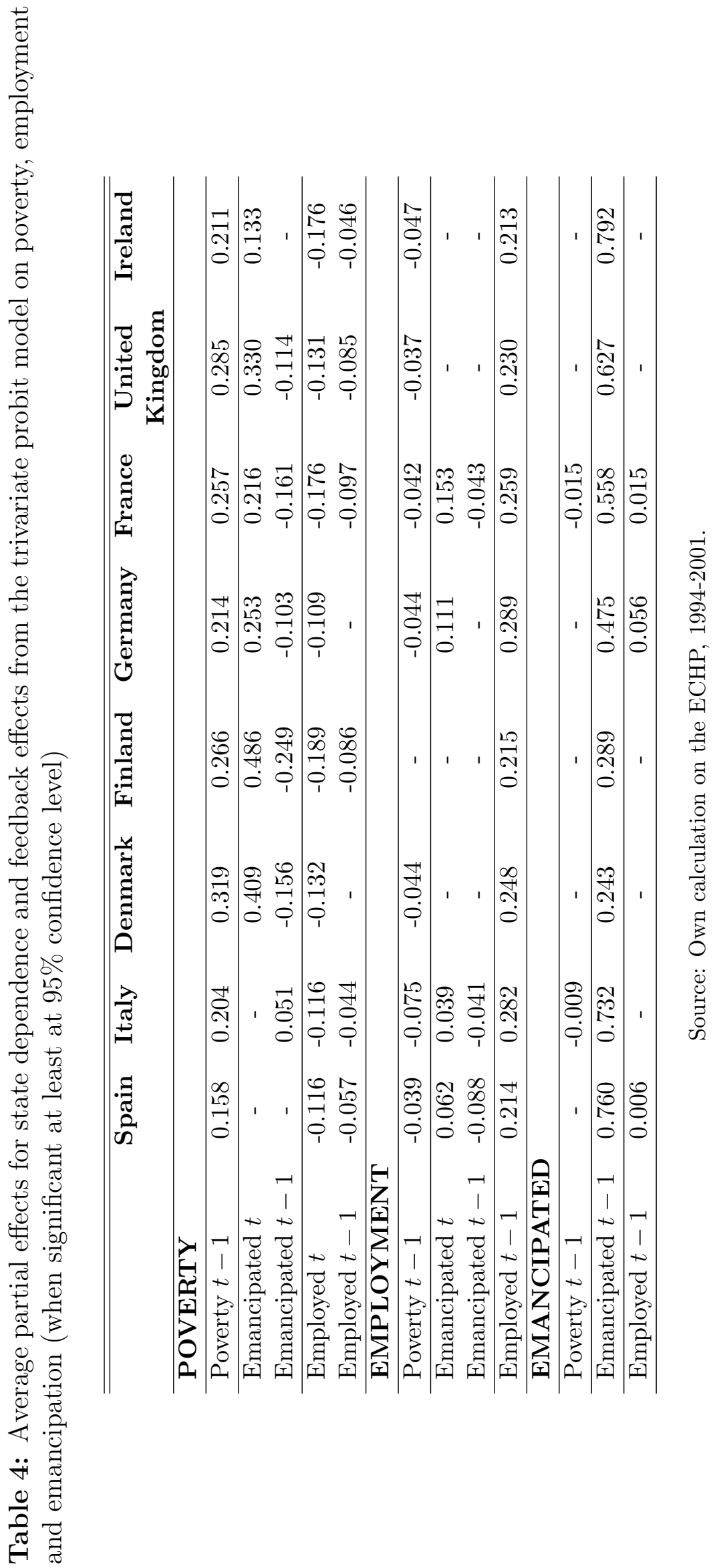




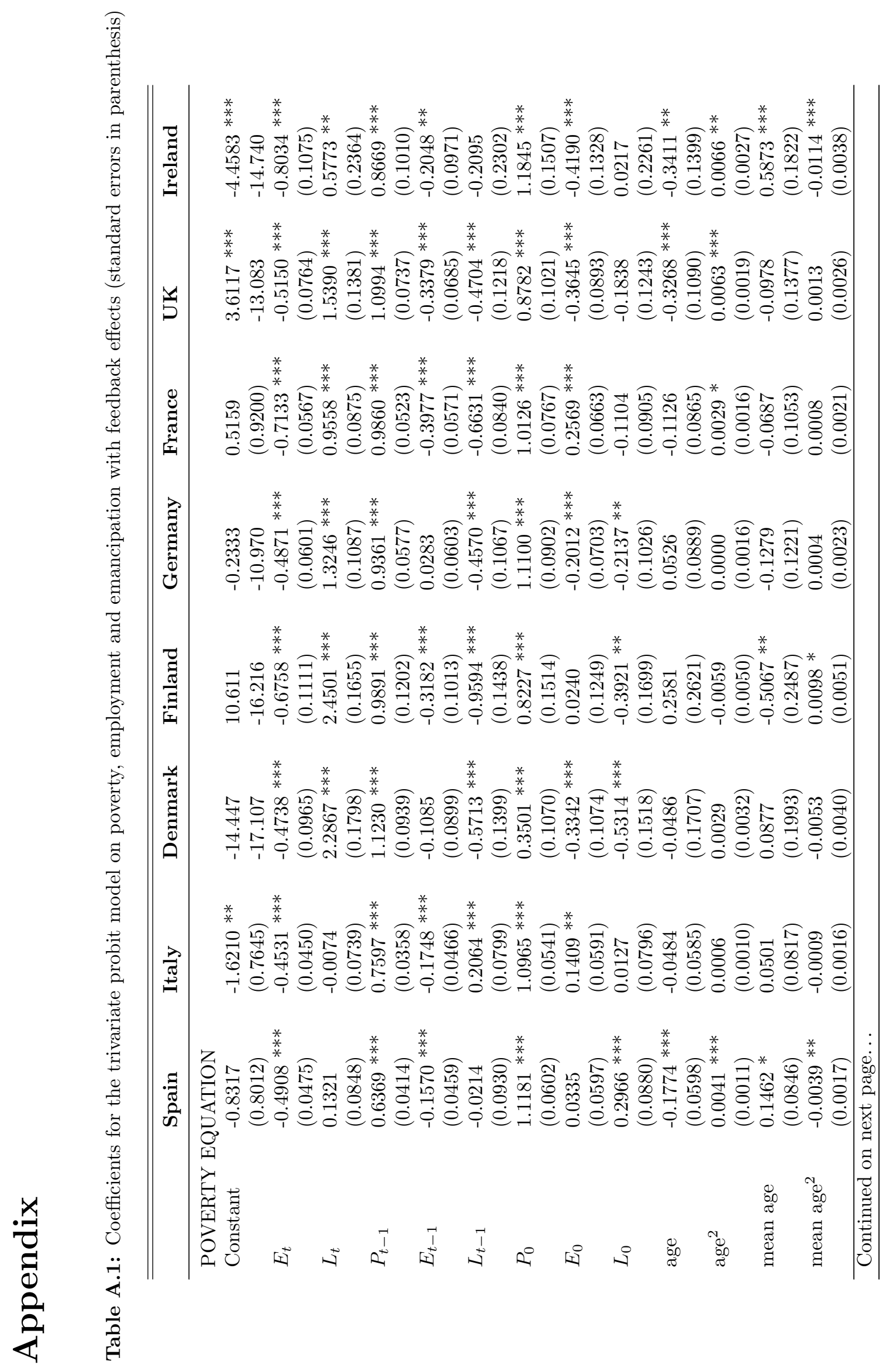




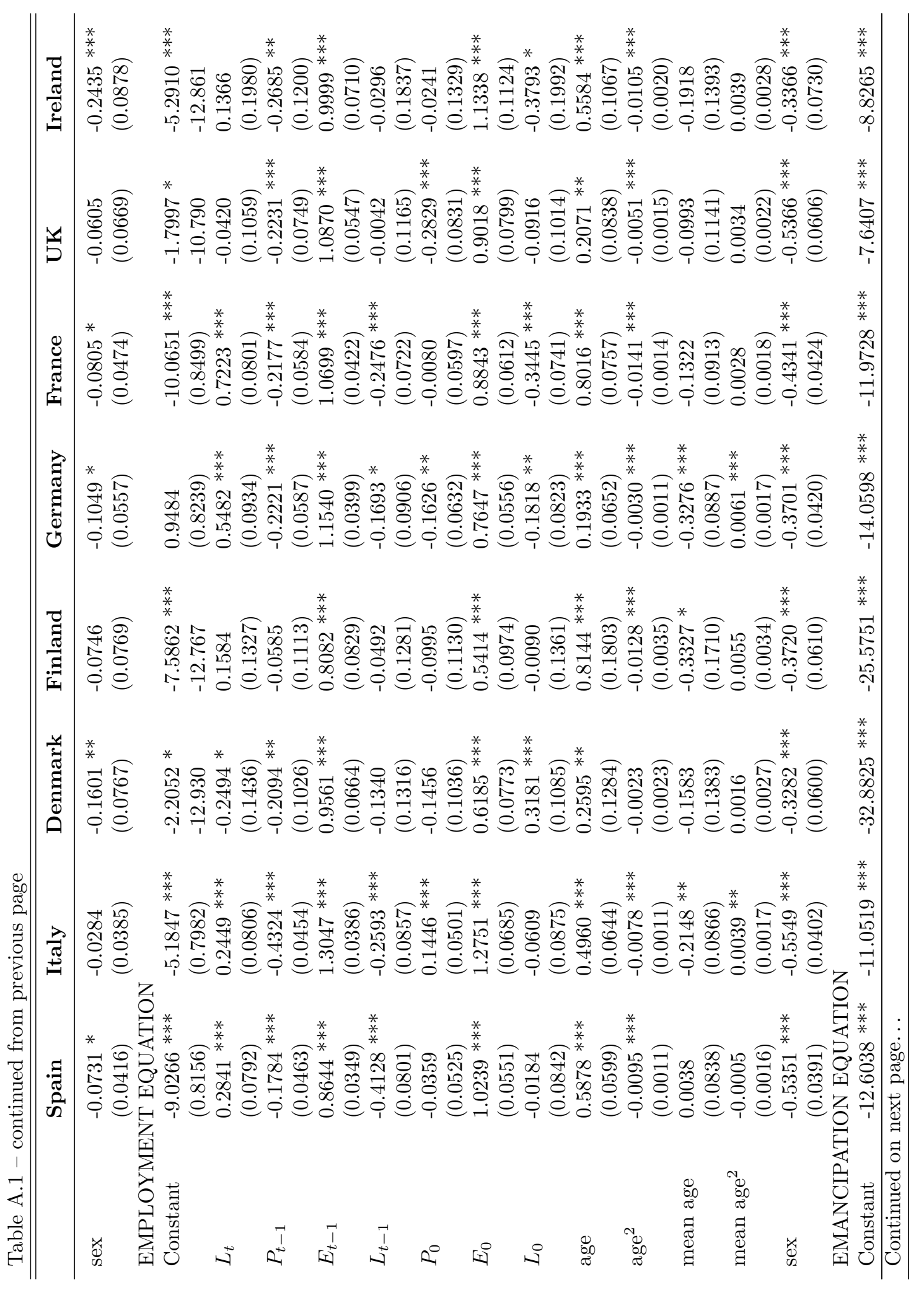




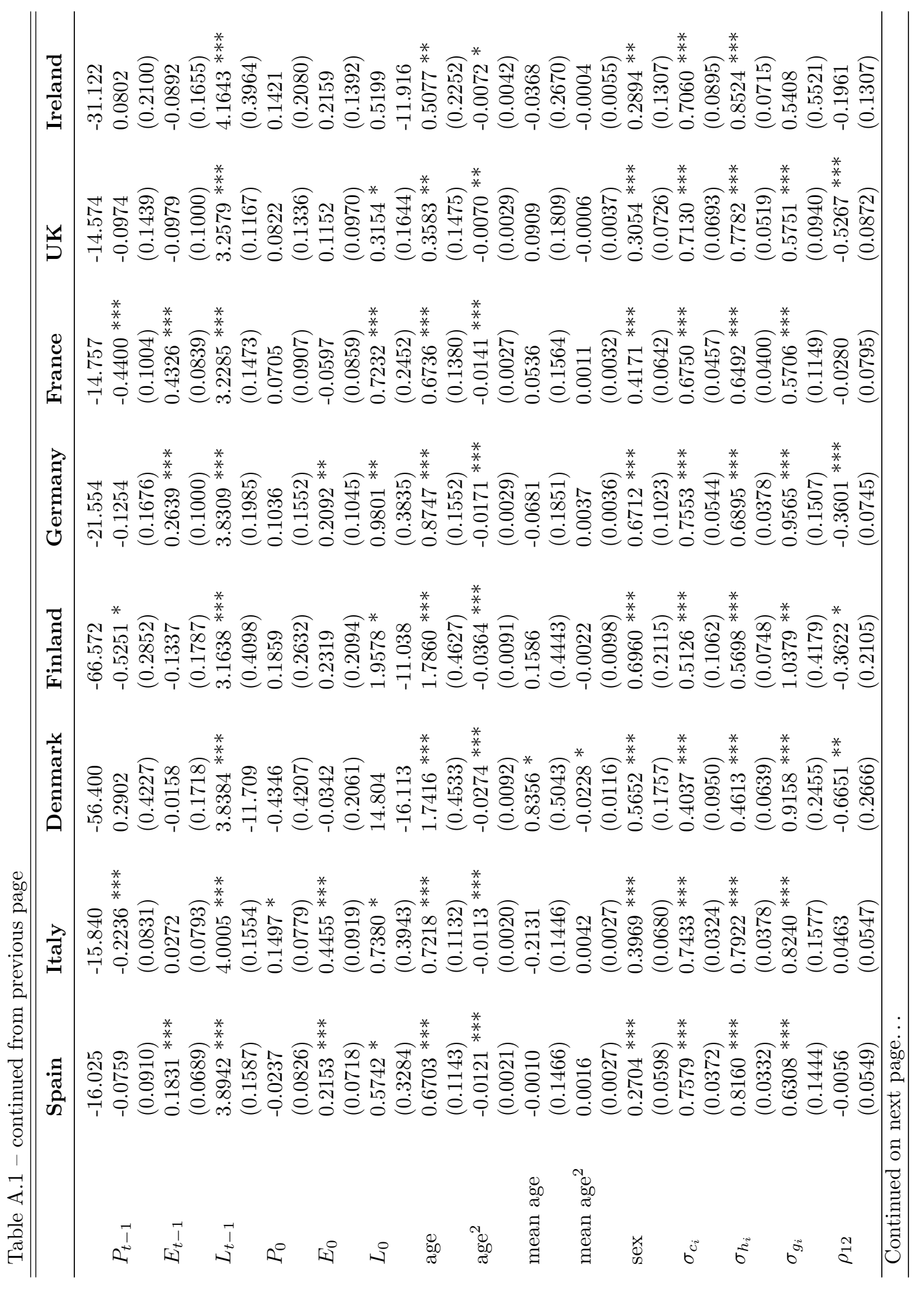




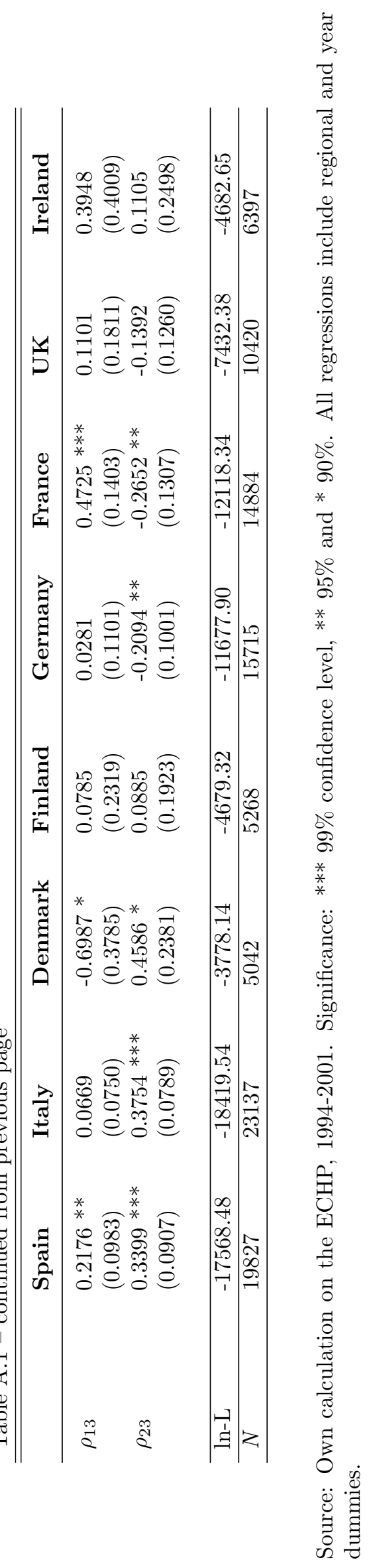

